\title{
Marketing to Minority Groups through MLB Coverage: An Examination of Two U.S. Sport Magazines
}

\author{
Andrea N. Eagleman
}

Major League Baseball (MLB) is the most racially diverse professional sport league in the United States out of the three largest leagues (Lapchick, 2009a, 2009b, 2009c). The U.S. Census Bureau (2008) reports that the racial makeup of the U.S. is also becoming increasingly diverse, and according toFahmy (2010), minorities continue to show increased buying power. Therefore, it is important to understand the extent to which sport media outlets are marketing to minority groups through their coverage of diverse athletes. This study employed a content analysis methodology and examined MLB coverage in Sports Illustrated and ESPN The Magazine over an eight-year time period. The findings revealed no statistically significant differences between the percentage of coverage given to White, Black, Latino, and Asian MLB players and the percentages of players from each race in the league, nor between the percentages of each race in the U.S. population. Both magazines exhibited a trend of focusing coverage on mostly White and Black MLB players over the last few years, however, and implications from the findings, limitations of the study, and ideas for future researchare explained in the discussion and conclusion sections.

\section{Introduction}

$\mathbf{I}$ $\mathrm{n}$ the United States, Major League Baseball (MLB) is consistently the most racially diverse professional sports league of the three largest leagues - MLB, the National Football League (NFL) and the National Basketball Association (NBA). With $60.4 \%$ White athletes, 10.2\% Black athletes, $27.0 \%$ Latino athletes, and $2.4 \%$ Asian athletes, MLB has a more diverse combination of three minority groups Black, Latino, and Asian - than the NFL (31\% White, $67 \%$ Black, $1 \%$ Latino, 2\% Asian) and the NBA (18\% White, $77 \%$ Black, 3\% Latino, $1 \%$ Asian), as both of those leagues have a strong mix of Black and White athletes, but very few Latino or Asian athletes (Lapchick, 2009a, 2009b, 2009c).

The MLB has seen an influx of minority baseball players over the years since the modern day racial integration of Black, Latino, and Asian players into the once all-White league(Riess, 2002).Homophily, or the idea that individuals tend to want to associate with others

Andrea N. Eaglema, $n$ Assistant Professor associated with the Department of Sport Management, Indiana University-Purdue University, Indianapolis, Indiana, USA. similar to themselves, would suggest that the increasing minority population of MLB players could lead to a more diverse MLB fan base as well (Currarini, Jackson, \& Pin, 2010).

Along with the MLB, the general U.S. population is also becoming increasingly diverse, as the U.S. Census Bureau (2008) projects that the percentage of Hispanic and Latino Americans will grow from the current figure of $15 \%$ of the population to $30 \%$ by the year 2050. Along with the increase in minority population, minorities also wield increasingly strong purchasing power. According to Fahmy (2010), the buying power of Hispanics in the U.S. is expected to increase by $50 \%$ over the next five years, Asian buying power by $42 \%$, and African American buying power by $25 \%$.

Because of the increase in both population and buying power for minorities in the U.S., along with the idea that consumers tend to associate with those who are most like themselves, it is important to understand whether sport media outlets such as ESPN The Magazine and Sports Illustrated are appealing to minority consumer groups by marketing diverse athletes through 
their magazines' coverage. When media outlets select certain sports or athletes to cover, they are essentially marketing their media outlet (magazine, newspaper, website, etc.) to consumersinterested in reading or learning about those specific sports or athletes. Eagleman, Pedersen, and Wharton (2009) explained that sport media outlets might be able to attract more consumers if their coverage is broadened to include a wider variety of athletes. Therefore, the purpose of this study was to examine how the two most popular generalinterest sport magazines in the U.S., Sports Illustrated and ESPN The Magazine, market to minority groups through their coverage of MLB players of differing race.

\section{Literature Review}

Many researchers have examined the amount of media coverage given to athletes of differing race, and Claringbould, Knoppers, and Elling (2004) asserted that minority athletes are often underrepresented in sports media outlets. A great deal of the past research on this topic found that the majority of sports media coverage focused on White male athletes (e.g., Billings \&Angelini, 2007; Billings \& Eastman, 2002; Billings \& Eastman, 2003; Duncan \&Messner, 1998; Eagleman \& McNary, in press). For example, Billings and Eastman (2002) found that television coverage of the 2000 Summer Olympics was largely skewed toward White athletes, as this racial group received over 1,200 more mentions than Black athletes throughout the duration of the Games. Similarly, several studies focusing on Sports Illustrated found that White athletes received more coverage than Black athletes (e.g., Condor \& Anderson, 1984; Lumpkin \& Williams, 1991; Primm, DuBois, \&Regoli, 2007). Condor and Anderson (1984) and Lumpkin and Williams (1991) both found that feature stories of White athletes were longer and more in-depth than those articles about athletes of other races. According to Van Sterkenburg and Knoppers (2004), because many sports journalists are White males, they in turn support middle and upper-class White men in their coverage. When sport media outlets focus their coverage on athletes of one race to the exclusion of athletes of other races, it "undermines the performances and achievements of minority and international athletes, and reinforces racial hierarchy structures in the U.S." (Eagleman, 2009, p. 107).

In terms of the type of coverage given to athletes of differing race, White male athletes have been shown to not only receive more coverage, but they are often portrayed more positively than other racial groups, such as achieving success because of their strong work ethic or intelligence (e.g., Billings \&Angelini, 2007; Billings \& Eastman, 2002; Billings \& Eastman, 2003; Larson \&Rivenburgh, 1991; Real \&Mechikoff, 1992).In a study of college basketball coverage, Wonsek (1992) also found that White athletes were often portrayed as natural team leaders. Conversely, Black athletes have been consistently portrayed as achieving success due to natural talent or biological advantages (e.g., Billings \& Eastman, 2002; Denham, Billings, \&Halone, 2002; Eastman \& Billings, 2001). Regarding Asian athletes, researchers have found this group to be portrayed as a model minority, a stereotype that portrays all Asians as successful in school and their careers, hard-working, and conforming to societal norms (Wong, Lai, Nagasawa, \& Lin, 1998). Researchers such as Mayeda (1999) and Nakamura (2005) found that sport media outlets portray Asian athletes in a stereotypical manner. Few researchers have examined media portrayals of Latino athletes. Of those who have examined this topic, Sabo, Jensen, Tate, Duncan, and Leggett (1996) studied television coverage of 31 different sporting events and found that portrayals of Latino athletes were mixed. Some portrayals were found to praise Latino athletes, while others dwelled on the physical differences of these athletes compared to other racial groups.

Along with the previous findings regarding media coverage of minority athletes, some scholars also examined the topic of marketing to minority groups in a sport setting. Clarke III and Mannion (2006) stated that sport franchises "habitually marketed their product to the 'typical' fan, sometimes neglecting minorities" (p. 23). They highlighted the need for sport organizations to market to diverse consumer groups, citing specifically the strong buying 
power of Asian Americans. Similarly, Armstrong (2000) argued that sport managers should attempt to better understand Black consumers in order to elicit stronger responses after these consumers are exposed to communication efforts from a sport organization. While these scholars noted a need for greater marketing efforts targeting minority groups, it is also important for sport organizations to learn "how to devise messages to appeal to the uniqueness of ethnic markets (as well as to youth, women, senior citizens, etc.) without being culturally insensitive, exploitative, or offensive" (Armstrong, 1999, p. 284). Similarly, Bryant (1993) urged sport businesses to develop an understanding of the ways in which targeting racial and ethnic populations "contribute to a universally better business strategy" (p. 197).

\section{Problem Statement}

It is unknown whether U.S.-based sport media outlets are marketing to minority groups through their media content.It is important to understand this because media outlets might be missing an opportunity to reach new market segments that were previously ignored, and could help readers of one race better understand people of differing races.It is also necessary for these media outlets to cover different racial or ethnic groups in order to mirror the changing patterns of race in American society.Therefore, the purpose of this study was to determine to what extent Sports Illustrated and ESPN The Magazine market minority MLB players through their coverage, given the rise in the number of minorities in the league as well as in the U.S. population.This study is significant because it could reveal inequitable coverage for some racial groups, as well as reveal that these magazines are not fully utilizing an opportunity to reach out to new market segments.Targeting such segments could lead to greater profits, a more diverse readership, and a greater understanding of different racial groups among readers.

\section{Research Questions}

The following five research questions guided this study:
RQ1 - What percentage of feature story coverage was devoted to MLB athletes of differing race in Sports Illustrated and ESPN The Magazine from 2000 to 2007?

RQ2 - What changes in coverage, if any, occurred over the eight-year time period?

RQ3 - Based on the coverage, which racial groups were the magazines targeting during the time period of the study?

RQ4 - Did statistically significant differences exist between the coverage of race and the racial makeup of the players in the league?

RQ5 - Did statistically significant differences exist between the coverage of race and the racial makeup of the U.S. population?

\section{Methodology}

This study employed a quantitative content analysis methodology, which is considered be an unobtrusive and nonreactive research method because content can be examined after it has been produced (Riffe, Lacy, \& Fico, 2005). Content analysis involves an examination of documents or other forms of written communication, and all content that is analyzed goes through an identical operational procedure (Stempel, 2003).

\section{Population Selection}

The population for this study included all issues of Sports Illustrated and ESPN The Magazine from the months of April through September during the years of 2000 through 2007. These months were chosen to reflect the MLB season, excluding the post-season during which time it was likely that only players from the eight teams advancing to post-season play would be covered. Selecting the months of April through September ensured that all MLB players had an equal chance of receiving coverage in the two magazines.

Every magazine during the aforementioned time period was coded for this study, yielding a total population size of 304 magazines, 201 of which were issues of Sports Illustrated and 103 of 128 
which were issues of ESPN The Magazine.It is important to note that the reason there were nearly double the amount of Sports Illustrated magazines is because it is a weekly publication, while ESPN The Magazine is a bi-monthly publication. From this population, a total of 204 articles were coded about MLB players.

\section{Measures}

Feature story articles appearing in the table of contents were considered the main units of analysis.The stories must have had a focus on one MLB athlete, therefore stories about multiple players, coaches, or team personnel were not coded. Feature stories were selected for analysis because of their perceived potential impact on a consumer's decision to purchase a magazine. Feature story headlines are often displayed prominently on a magazine's cover, which is the first aspect of a magazine that a consumer sees when it is on the newsstand. Therefore, feature stories could be considered a marketing tool in attracting consumers to purchase the magazine.

A coding protocol was designed specifically for this study, containing the following variables to be coded for each story: magazine name, magazine date, title of the article, author's name, article prominence, starting page number of article, number of pages of the article, number of photos attached to the story, featured athlete's name, featured athlete's race, athlete's on-field position, athlete's age at the time of publication, number of years in the league, featured athlete's team at the time of the publication, and whether or not the athlete was featured on the cover of the magazine.

When determining an athlete's race, there were very few instances in which the race was questioned by the coders. When these instances occurred, however, the coders were instructed to read the article in an attempt to find out if the athlete self-defined his race in a quote. If the athlete did not self-describe, the coders were then instructed to find out if the author defined the athlete to be a certain race in the text. In all questionable instances these methods successfully determined the athlete's race.

\section{Coders}

The researcher and a communication professional served as the two coders for this study. Both coders had successfully coded for the same content analysis research studies in the past, and therefore were deemed to be experienced coders. Following coder training sessions, the two divided a sample of the magazines to code independently of each other in order to test for reliability.

\section{Reliability}

Inter-coder reliability was calculated both by percentage agreement and using Cohen's (1960) kappa to control for change agreement. Using $10 \%$ of the total population, the two coders used the coding protocol and codebook to independently code the magazines. In terms of percentage agreement, reliability figures ranged from $88.9 \%$ to $100 \%$. Then, using Statistical Package for the Social Sciences (SPSS) Version 18, kappa was determined for every variable, with results ranging from 0.79 to 1.00 in all categories. These numbers were deemed acceptable for moving on with the study, as Wimmer and Dominick (2006) suggest that the kappa coefficient must be at least 0.75 in order to continue the study.

Following the inter-coder reliability procedures, each coder received 137 randomly selected issues from the remaining magazine population, and these magazines were coded independently of each other.

\section{Results}

Five research questions guided this study, and the results of each question are presented and discussed below.

Research question one asked what percentage of feature story coverage was devoted to MLB athletes of differing race in the two magazines from 2000 to 2007. The findings revealed that over the eight-year time period of the study, Sports Illustrated devoted $42.5 \%$ of its coverage to White MLB players, $30.1 \%$ to Latino players, $23.9 \%$ to Black players, and $3.5 \%$ to Asian 
players. In contrast, ESPN The Magazine devoted $49.5 \%$ of its coverage to White players, $25.3 \%$ to Latino players, $22.0 \%$ to Black players, and $3.3 \%$ to Asian players. When the

Table 1

Coverage Devoted to MLB Athletes of Differing Race, 2000-2007

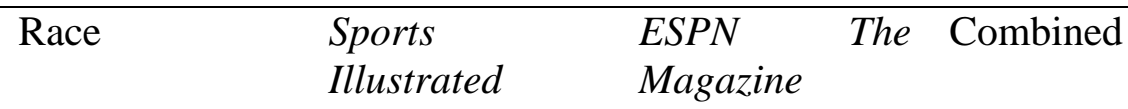

\begin{tabular}{llll} 
White & $42.50 \%$ & $49.50 \%$ & $45.60 \%$ \\
Latino & $30.10 \%$ & $25.30 \%$ & $27.50 \%$ \\
Black & $23.90 \%$ & $22.00 \%$ & $23.50 \%$ \\
Asian & $3.50 \%$ & $3.30 \%$ & $3.40 \%$ \\
\hline
\end{tabular}

The second research question asked what Table 2 for the complete results.It should be changes in coverage occurred over the eightyear time period of the study.The results revealed that no clear patterns of coverage emerged over the time period of the study.See Table 2 coverage in either magazine during the years of 2000, 2004, 2005, 2006, and 2007. data from both magazines was combined, the total percentage devoted to each race was $45.6 \%$ White, $27.5 \%$ Latino, 23.5\% Black, and 3.4\% Asian.

Year-by-Year Coverage of MLB Players Based on Race

\begin{tabular}{lllll}
\hline Year & White & Black & Latino & Asian \\
& & & & \\
2000 & $55.13 \%$ & $21.87 \%$ & $25.00 \%$ & $0.00 \%$ \\
2001 & $44.45 \%$ & $14.81 \%$ & $33.33 \%$ & $7.41 \%$ \\
2002 & $39.39 \%$ & $18.18 \%$ & $30.30 \%$ & $12.12 \%$ \\
2003 & $36.00 \%$ & $24.00 \%$ & $36.00 \%$ & $4.00 \%$ \\
2004 & $52.00 \%$ & $16.00 \%$ & $32.00 \%$ & $0.00 \%$ \\
2005 & $43.75 \%$ & $25.00 \%$ & $31.25 \%$ & $0.00 \%$ \\
2006 & $54.55 \%$ & $31.82 \%$ & $13.64 \%$ & $0.00 \%$ \\
2007 & $41.67 \%$ & $37.50 \%$ & $13.64 \%$ & $0.00 \%$ \\
\hline
\end{tabular}

Research question three sought to discover which racial groups were targeted during the time period of the study based on the coverage. When looking at the overall results (see Table 1), it appears that all groups were targeted, as every racial group received coverage over the time period of the study. The fourth research question asked if statistically significant differences existed between the coverage of race and the racial makeup of the players in Major League Baseball.Chi square analysis revealed that no statistically significant results existed at the .05 level $\left(x^{2}=4.89, d f=3, p>.05\right)$.Please note that this reflects the overall coverage and not year-

When looking at this question from a year-toyear perspective (see Table 2), it appears that Whites and Blacks are currently being targeted by the two magazines due to the higher percentage of coverage focusing on MLB players of these two races.

by-year. When chi square analysis was conducted on each individual year, only one year (2002) had a statistically significant difference $\left(x^{2}=7.32, d f=3, p<.05\right)$.

Research question five sought to determine whether statistically significant differences existed between the coverage of race and the 
racial makeup of the U.S. population.Similar to the results from research question four, chi square tests revealed that no statistically significant differences existed at the .05 level $\left(x^{2}\right.$ $=1.26, d f=3, p>.05)$.

The following sections will discuss these results in greater detail and offer suggestions for further research on this topic.

\section{Discussion}

This study sought to determine to what extent Sports Illustrated and ESPN The Magazine market minority MLB players through their feature story coverage given the rise in the number of minorities in the league as well as in the U.S. population.Although there were no statistically significant differences in the number of athletes of each race featured and the number of athletes of each race in the league, it is important to note that year-specific data showed that the bulk of coverage over the last two years of the study focused heavily on White and Black athletes.This shows that the magazines are targeting a White and Blackreadership via their coverage of White and Black MLB players, and are leaving out Latino and Asian baseball fans, or minimizing these fans' exposure to stories about players of their own race and/or culture.It is also interesting to note the rise in coverage of Black MLB players given the decrease in the percentage of Black MLB players in the league, as well as the decrease in coverage of Latino players over the last two years of the study, as this group constitutes the second-largest racial group in MLB. While the reason for increased coverage of Black athletes and decreased coverage of Latino athletes is unknown, it is possible that this is a reflection of the magazines promoting U.S.-born players to the exclusion of international players. All but one of the feature stories about Black MLB players focused on U.S.-born athletes, while there was a greater mix of U.S.-born and international Latino athletes featured. These findings reveal that the two sport magazines, Sports Illustrated and ESPN The Magazine, are not fully utilizing an opportunity to reach out to new market segments, which could lead to greater profits, a more diverse readership, and a greater understanding of minority groups among all readers.

As mentioned in the literature review, it is important that sport marketers learn and utilize methods of appealing to diverse racial groups. A survey of Latinos living in the U.S. revealed that $61 \%$ consider themselves to be fans of Major League Baseball (World, 2005). Additionally, the Magazine Publishers of America (2007) reported that Latinos "engage more with magazines than with other major media" (p. 13).Both of these points highlight the opportunity for media outlets such as Sports Illustrated and ESPN The Magazine to reach out to these Latino sport consumers via the coverage in their magazines, especially in a time in which the Latino population and purchasing power are both on the rise. Based on the theory of homophily, it is reasonable to assume these Latino sport consumers would be more likely to purchase the magazines if they knew they would be able to read about athletes similar to them. Likewise, Li (2003) found that Asian consumers shop more frequently than other demographic groups, and Wiesendanger (1993) found that Asians relate to marketing messages in which they can identify their culture. The Magazine Publishers of America (2006) reported that "nearly three out of four Asian-American adults are magazine readers" (p. 12). These findings also seem to suggest that more coverage of Asian athletes in sport magazines could lead to greater consumption of these magazines by Asian sport consumers. The only years in which Asian MLB players received feature story coverage in the two magazines, however, were 2001, 2002, and 2003, despite the number of Asian MLB players increasing over the time period of the study.

Based on the results of this study, it appears that in comparison to previous literature, the proportion of coverage devoted to minority athletes is increasing in the magazines examined.Comparing the coverage of the two magazines, it appears that Sports Illustrated devoted more coverage to minority players, and therefore might appeal to a broader racial demographic base than its competitor, ESPN The Magazine.The latter magazine could potentially gain new subscribers and readers 
from different backgrounds if it broadened its coverage of minority MLB players.Based on these findings, it is not surprising that Sports Illustrated is the fifth most read magazine by Latinos and the ninth most read magazine by Blacks (Magazine Publishers of America, 2007, 2008).ESPN The Magazine is the number 11 most-read magazine by Blacks, and did not make the list of magazines read by Latinos. Neither magazine appeared on the list of top magazines read by Asian Americans, and the only sport-related magazine that made the list was Tennis, in the number four spot (Magazine Publishers of America, 2006).

The racial makeup of Sports Illustrated and ESPN The Magazine subscribers is unknown.Neither magazine reports these figures on its website, nor is the information available in the Audit Bureau of Circulations publisher's statement for either magazine.Although this information is unknown, it is thought that both magazines could benefit from including more racially diverse coverage, thus marketing the magazines to racial groups who might be interested in reading about athletes of the same race.

\section{Conclusion}

This study is valuable for sport media businesses, particularly Sports Illustrated and ESPN The Magazine, because it reveals which racial groups the magazines appear to be targeting via their content, and reveals an opportunity to target a more diverse readership through increased feature story coverage of athletes from minority groups, particularly Latinos and Asians.

While the results of this research are important and can prove to be helpful to sport media managers, the study does have some limitations that merit discussion.First, this study only looked at articles about MLB players in the two magazines. Therefore, the results and discussion of the results are only applicable to the magazines' MLB coverage and not coverage of other sports and athletes, such as professional and intercollegiate football, basketball, hockey, soccer, tennis, and auto racing.It is recommended that future researchers examine the entire content of these magazines to determine whether diverse racial groups are targeted via articles and content about sports other than baseball.Another limitation of this study is that its findings are only applicable to the time period of 2000 through 2007, as these were the years the magazines were examined.

As previously mentioned, future research should broaden the current study to include all sports featured in the two magazines.Additionally, examining the advertisements from the two publications might reveal more about which groups the magazines are targeting. Along with content analysis studies, it would also be helpful to study different racial groups'perceptions of the two magazines and these consumers' reasons for purchasing or not purchasing the magazines.Studying the effects of sport marketing on White, Black, Latino, and Asian sport consumers' purchasing decisions could reveal information useful to sport marketers wishing to target new consumer bases. Finally, magazine editors and journalists could be surveyed to reveal the decision-making processes that determine which athletes are covered, and conversely, which athletes are not covered.

This study revealed the reporting practices of MLB players employed by the two most popular general-interest sport magazines in the U.S.Its findings serve as a resource for sport media managers wishing to target a broader racial audience, and also serve as a solid foundation for future research on the topic.

\section{References}

Armstrong, K.L. (1999). Nike's communication with Black audiences.Journal of Sport \& Social Issues, 23(3), 266-286.

Armstrong, K.L. (2000). African-American students' responses to race as a source cue in persuasive sport communications. Journal of Sport Management, 14, 208-226.

Billings, A.C., \&Angelini, J.R. (2007).Packaging the Games for viewer consumption: Gender, ethnicity, and nationality in NBC's coverage of the 2004 Summer Olympics.Communication Quarterly, 55(1), 95111. 
Billings, A.C., \& Eastman, S.T. (2002).Selective representation of gender, ethnicity, and nationality in American television coverage of the 2000 Summer Olympics.International Review for the Sociology of Sport, 37(3-4), 351-370.

Billings, A.C., \& Eastman, S.T. (2003).Framing identities: Gender, ethnic, and national parity in network announcing of the 2002 Winter Olympics.Journal of Communication, 53(4), 569-586.

Bryant, J.E. (1993). Sport management and the interdependence with sport sociology: Sport as a social product. Journal of Sport Management, 7, 194-198.

Claringbould, I., Knoppers, A., \&Elling, A. (2004). Exclusionary practices in sport journalism. Sex Roles, 51(11/12), 709-718.

Clarke III, I., \&Mannion, R. (2006).Marketing sport to Asian-American consumers.Sport Marketing Quarterly, 15, 20-28.

Cohen, J.A. (1960). Coefficient of agreement for nominal scales.Educational and Psychological Measurement, 20, 37-46.

Condor, R., \& Anderson, D.F. (1984). Longitudinal analysis of coverage accorded black and white athletes in feature articles of Sports Illustrated (1960-1980). Journal of Sport Behavior, 7(1), 39-43.

Currarini, S., Jackson, M.O., \& Pin, P. (2010).Identifying the roles of race-based choice and chance in high school friendship network formation. Proceedings of the National Academy of Sciences of the United States of America, 107(11), 4857-4861.

Denham, B.E., Billings, A.C., \&Halone, K.K. (2002). Differential accounts of race in broadcast commentary of the 2000 NCAA Men's and Women's Final Four Basketball Tournament. Sociology of Sport Journal, 19, 315-332.

Duncan, M., \&Messner, M. (1998). Media images of gender and sport. In L. Wenner (Ed.), MediaSport(pp. 170-185). London: Routledge. Eagleman, A.N. (2009). Do the best MLB athletes receive coverage regardless of race and nationality? A content analysis of sport magazines.Journal of Contemporary Athletics, 4(2), 89-109.

Eagleman A.N., \& McNary, E.L. (In Press). Gender, race, and nationality: An examination of print coverage of the 2006 Winter
Olympics.InDolles, H., \&Soderman, S. (Eds.),Sport as a Business: International, Professional and Commercial Aspects. New York, NY: PalgraveMacMillon.

Eagleman, A.N., Pedersen, P.M., \& Wharton, R. (2009). Coverage by gender in ESPN The Magazine: An examination of articles and photographs. International Journal of Sport Management, 10, 226-242.

Eastman, S.T., \& Billings, A.C. (2001). Biased voices of sports: Racial and gender stereotyping in college basketball announcing. Howard Journal of Communication, 12(4), 183-204.

Fahmy, S. (2010, November 4). Despite recession, Hispanic and Asian buying power expected to surge in U.S., according to annual UGA Selig Center multicultural economy study. Retrieved from http://www.terry.uga.edu/news/releases/2010/mi nority-buying-power-report.html

Lapchick, R. (2009a). The 2009 Racial and Gender Report Card: Major League Baseball. Retrieved from http://www.tidesport.org/RGRC/2009/2009_ML B_RGRC_PR_Final_rev.pdf

Lapchick, R. (2009b). The 2009 Racial and Gender Report Card: National Basketball Association. Retrieved from http://www.tidesport.org/RGRC/2009/2009_NB

A_RGRC_PR_UPDATED.pdf

Lapchick, R. (2009c).The 2009 Racial and Gender Report Card: National Football League. Retrieved from http://www.tidesport.org/RGRC/2009/2009_NF

\section{L_RGRC.pdf}

Larson, J.F., \&Rivenburgh, N.K. (1991). A comparative analysis of Australian, U.S. and British telecasts of the Seoul Olympic Ceremony. Journal of Broadcasting and Electronic Media, 35(1), 75-94.

$\mathrm{Li}, \mathrm{K}$. (2003). The A list.The Magazine for Magazine Management, 32(5), 30-33.

Lumpkin, A., \& Williams, L.D. (1991). An analysis of Sports Illustrated feature articles, 1954-1987. Sociology of Sport Journal, 8(1), 16-32.

Magazine Publishers of America.(2008). African-American/Black Market Profile. Retrieved from http://www.magazine.org/ASSETS/2457647D5 D0A45F7B1735B8ABCFA3C26/market_profil e_Black.pdf 
Magazine Publishers of America.(2006). AsianAmerican Market Profile. Retrieved from http://www.magazine.org/ASSETS/BF4E8BCE 5E9D4847BA537A448EE20EF4/market_profil e_asian.pdf

Magazine Publishers of America.(2007). Hispanic/Latino Market Profile. Retrieved from http://www.magazine.org/ASSETS/C0724E188 C664BE88305971FE6BBCD80/MPAHispMktP ro.pdf

Mayeda, D.T. (1999). From model minority to economic threat: Media portrayals of Major League Baseball pitchers Hideo Nomo and Hideki Irabu. Journal of Sport \& Social Issues, 23(2), 203-217.

Nakamura, Y. (2005). The samurai sword cuts both ways: A transnational analysis of Japanese and US media representations of Ichiro. International Review for the Sociology of Sport, 40(4), 467-480.

Primm, E., DuBois, S., \&Regoli, R. (2007). Every picture tells a story: Racial representation on Sports Illustrated covers. Journal of American Culture, 30(2), 222-231.

Real, M.R., \&Mechikoff, R. (1992). Deep fan: Mythic identification, technology, and advertising in spectator sports. Sociology of Sport Journal, 9(4), 323-339.

Riess, S. (2002). Baseball and ethnicity. In Odell, J. (Ed.), Baseball as America: Seeing ourselves through our national game (pp. 8889). Washington, DC: National Geographic.

Riffe, D., Lacy, S., \& Fico, F.G. (2005).Analyzing media messages: Using quantitative content analysis in research (2nd ed.). Mahwah, NJ: Lawrence Erlbaum.
Sabo, D., Jansen, S.C., Tate, D., Duncan, M.C., \& Leggett, S. (1996). Televising international sport: Race, ethnicity, and nationalistic bias.Journal of Sport \& Social Issues, 20, 7-21. Stempel, G.H. (2003). Content analysis.In G.H. Stempel, D.H. Weaver, \& G.C. Wilhoit(Eds.), Mass communication research and theory (pp. 209-219). Boston: Pearson Education, Inc.

U.S. Census Bureau (2008). Projections of the population by sex, race, and Hispanic origin for the United States: 2010 to 2050. Retrieved from http://www.census.gov/population/www/project ions/files/nation/summary/np2008-t4.xls

Van Sterkenburg, J., \&Knoppers, A. (2004).Dominant discourses about race/ethnicity and gender in sport practice and performance.International Review for the Sociology of Sport, 39(3), 301-321.

Wiesendanger, B. (1993). Asian-Americans: The three biggest myths. Sales \& Marketing Management, 145(11), 86-90.

Wimmer, R.D., \& Dominick, J.R. (2006).Mass media research: An introduction.Belmont, CA: Thomson Wadsworth.

Wong, P., Lai, C.F., Nagasawa, R., \& Lin, T. (1998). Asian Americans as a model minority: Self-perceptions and perceptions by other racial groups. Sociological Perspectives, 41(1), 95118.

Wonsek, P.L. (1992). College basketball on television: A study of racism in the media. Media, Culture, and Society, 14, 449-461.

World Congress of Sports (2005).Street \& Smith's SportsBusiness Journal, 8(46), 33-35. 